\title{
FORMAÇÃO CONTINUADA NA EDUCAÇÃO INFANTIL: INTERFACES COM O BRINCAR
}

\author{
L. C. SOARES*, V. Côco e S. VENTORIM
Universidade Federal do Espírito Santo - UFES
leticiacavassana @ hotmail.com* \\ Artigo submetido em janeiro/2016 e aceito em janeiro/2016 \\ DOI: $10.15628 /$ holos.2016.3953
}

\section{RESUMO}

Considerando a formação continuada em articulação com o trabalho educativo na Educação Infantil, pautado no eixo das interações e brincadeiras, neste texto apresentamos estudo bibliográfico que analisou produções acadêmicas sobre as temáticas da formação continuada e do brincar, situadas na primeira etapa da educação básica. Sustentados nos pressupostos teóricometodológicos bakhtinianos, buscamos compreender como se configuram as pesquisas que associam a tríade referente à formação continuada, ao brincar e à Educação Infantil, selecionando trabalhos no Banco de Teses e Dissertações da CAPES, nos Grupos de trabalho 07 e 08 da ANPEd e no banco da SciELO. As análises do corpus de dados acenam para a necessidade de investimentos em ações de formação continuada que tematizem o brincar na interface com o trabalho educativo com as crianças, com a finalidade de culminar em práticas pedagógicas pautadas na brincadeira.

PALAVRAS-CHAVE: Educação Infantil, Formação continuada, Brinca deira

\section{CONTINUED FORMATION IN THE EDUCATION OF CHILDREN: INTERFACES WITH PLAYING}

\begin{abstract}
Considering the articulation between continued formation and the educative work in the Education of Children, based on the axis of interactions and plays, in this text we present a bibliographic study which analyzed academic productions about the topics of continued formation and the act of playing, present in the first level of basic education. Based on bakhtinian theoretical methodological approaches, we aimed to understanding in which manner the researches that associate continued
\end{abstract}

formation, the act of playing, and the Education of Children are conducted, selecting works from CAPES Theses and Dissertations database, from the 07 and 08 ANPEd groups of study, and from SciELO database. The analysis of the data corpus point to the necessity of investments on continued formation actions related to the act of playing and its interface with the educative work with children, in order to achieve pedagogical practices based on playing.

KEYWORDS: Education of Children, Continued Formation, Play. 


\section{INTRODUÇÃO}

Integrando a dialogia sobre produções acadêmicas que tematizam acerca da formação de professores e da Educação Infantil (EI) no contexto brasileiro (ANDRÉ, 2002; BRZEZINSKI, GARRIDO, 2006; BRZEZINSKI, 2014; ROCHA, 1999; e outros), neste artigo apresentamos estudo bibliográfico que focaliza a formação continuada no campo da El na interface com a brincadeira. Nessa proposição, sustentada no reconhecimento das brincadeiras como eixo da ação educativa na EI (BRASIL, 2009), buscamos trabalhos no Banco de Teses e Dissertações da Coordenação de Aperfeiçoamento de Pessoal de Nível Superior (CAPES), nos Grupos de Trabalho Educação de crianças de 0 a 06 anos (GT07) e Formação de professores (GT08) da Associação Nacional de PósGraduação e Pesquisa em Educação (ANPEd), bem como no banco da Scientific Electronic Library Online (SCIELO), com o intuito de analisar as pesquisas tendo em vista a importância de tematizar o brincar nos processos de formação continuada na El. A justificativa para a escolha desses bancos reside em sua importância quanto ao fomento à produção acadêmica e à divulgação desta no cenário brasileiro.

Sendo assim, elencamos como questões orientadoras: como se configura a articulação entre as temáticas da formação continuada de professores e do brincar na El nas pesquisas científicas no cenário brasileiro? Quais concepções de formação, brincadeira e El orientam essas pesquisas? Quais aspectos ganham destaque nos trabalhos, no que se refere à formação continuada e à brincadeira na EI? Com essas indagações, buscamos analisar os trabalhos, objetivando identificar contribuições para o campo da formação de professores dirigidas à sua articulação com o brincar.

Compreendendo que a produção acadêmica reúne várias vozes, compondo uma diversidade de enunciados, nosso diálogo com os estudos se pauta na noção de que "todo enunciado concreto é um elo na cadeia da comunicação discursiva de um determinado campo [...]. Uns conhecem os outros e se refletem mutuamente uns nos outros" (BAKHTIN, 2011, p. 296-297). Nessa perspectiva, entendemos que, nas abordagens das temáticas aqui focalizadas, podemos encontrar pontes de contato, aproximações, distanciamentos, confrontos, dentre as muitas formas de posicionamentos. Com isso, sustentados pelo referencial teórico-metodológico bakhtiniano, propomos um encontro entre distintos interlocutores que marcam os já ditos nos acúmulos do campo da formação no contexto da El, aventando que ainda há muito a se dizer no escopo da discussão voltada a possíveis diálogos entre a formação continuada e o brincar, no contexto da El.

Com nosso referencial, priorizamos uma postura de alteridade no que diz respeito às palavras e às experiências do outro, apostando num movimento de trocas de saberes na interlocução entre os textos selecionados. Nesse sentido, assinalamos também uma dialogia com os marcos legais que demarcam a centralidade da brincadeira, juntamente com interação, nas práticas pedagógicas na EI (BRASIL, 2009), bem como a definição da formação continuada como um direito dos profissionais da educação (BRASIL, 2015). Nesse sentido, partimos da premissa de que a brincadeira consiste numa ação primordial para o desenvolvimento e a aprendizagem na infância (VYGOTSKY, 1994), vivificando o trabalho educativo na El. Este, por sua vez, se sustenta 
nos processos formativos de seus quadros profissionais, que vêm assinalando a importância de mobilizar uma formação baseada na partilha de saberes entre pares profissionais (NÓ VOA, 2002).

Com esses pressupostos, organizamos este estudo de modo a explorar os acúmulos de cada banco, considerando, primeiramente, as pesquisas apuradas no Banco da CAPES, em seguida, os trabalhos apresentados nas reuniões dos GTs 07 e 08 da ANPEd e, por fim, as pesquisas selecionadas na SCIELO. Nessa sequência, empreendemos em cada banco de dados a apresentação dos estudos selecionados (destacando a regionalidade, os objetivos, as metodologias utilizadas, os referenciais teóricos adotados e os principais resultados e sínteses desenvolvidas), a análise das concepções sobre o brincar e sobre a formação e, com isso, a observação da articulação dessas temáticas. Assim, conseguimos evidenciar as distintas formas de configuração das produções.

Nessa arquitetônica, avançamos para a abordagem dos estudos que integram o primeiro banco elencado para a abordagem das pesquisas, perspectivando vinculações entre a formação continuada e o brincar na El.

\section{A FORMAÇÃO E O BRINCAR NA EDUCAÇÃO INFANTIL NAS PESQUISAS DA CAPES}

Com o intuito de relacionar as pesquisas que contemplam a formação, o brincar e a El no banco de dados da CAPES $^{1}$, começamos por apresentar um panorama dos procedimentos que culminaram na identificação dos estudos selecionados. Inicialmente, encaminhamos um levantamento geral que identificou 14.962 trabalhos sobre formação, 920 pesquisas no campo da Educação Infantil e 155 registros quanto aos trabalhos que abordam o brincar. Nesse repertório de produções, empreendemos uma busca mais específica a partir dos descritores associados Formação, Brincar ${ }^{2}$ e Educação Infantil, apurando 18 pesquisas. Analisando o contexto de produção de cada estudo, observa-se a presença das regiões Nordeste (50\%), Sudeste (28\%) e Sul (22\%).

Com as leituras detalhadas de cada produção, identificamos as focalizações temáticas, compondo dois grupos. Um primeiro grupo de trabalhos, ainda que eventualmente mencionasse a formação continuada e o brincar, não abarcava diretamente as temáticas aqui priorizadas, evidenciando temas mais ligados à formação inicial, à educação especial, à aquisição de leitura e escrita, à arquitetura escolar, entre outros. Focalizando o entrecruzamento das temáticas elencadas, compomos um segundo grupo, formado de três trabalhos (COELHO, 2012; FARIAS, 2012; NEITZEL, 2012) que demarcam a vinculação da formação continuada com a brincadeira no

\footnotetext{
1 A Coordenação de Aperfeiçoamento de Pessoal de Nível Superior (CAPES), fundação do Ministério da Educação (MEC), empreende a avaliação da pós-graduação stricto sensu, acesso e divulgação da produção científica, investimentos na formação de recursos de alto nível no país e no exterior, promoção da cooperação científica internacional, bem como indução e fomento da formação inicial e continuada de professores para a educação básica nas modalidades presencial e a distância. As informações bibliográficas das dissertações de mestrado e das teses de doutorado publicadas são fornecidas diretamente à CAPES pelos programas de pós-graduação de todo o país. No momento da busca, apenas os trabalhos defendidos em 2012 e 2011 estavam disponíveis, devido a uma verificação dos dados do sistema.

${ }^{2}$ Cabe observar que, no processo de busca dos trabalhos, utilizamos também o descritor Brincadeira em substituição a o descritor Brincar, aventando a possibilidade de agregar um conjunto distinto de estudos. Entretanto, a pesquisa com esse termo apurou um conjunto de produções já identificadas no levantamento inicial, indicando que os termos são, geralmente, abordados de modo associado.
} 
contexto da El. Tais pesquisas são oriundas das regiões Nordeste (COELHO, 2012; FARIAS, 2012) e Sul do país (NEITZEL, 2012), concluídas no ano de 2012 como dissertações de mestrado.

Avançando no encaminhamento de nosso estudo, propomos a interlocução entre os três trabalhos selecionados no segundo grupo objetivando captar as especificidades de cada pesquisa, com o propósito de compreender as principais ideias comunicadas pelos trabalhos e, nesse sentido, apresentar os objetivos, as metodologias adotadas, os referenciais teóricos utilizados, os principais resultados e as sínteses desenvolvidas pelos autores. Com isso, procuramos identificar as concepções acerca do brincar e da formação nos textos, compreendendo também como as pesquisas articulam essas temáticas. Nesta lógica, passamos a sintetizar nossas considerações acerca de cada pesquisa.

Abordando a interface entre a formação continuada de professores e os sentidos produzidos por estes acerca do brincar, Coelho (2012) empreende uma pesquisa crítica de colaboração de abordagem sócio-histórico-cultural para compreender a repercussão dos processos formativos na atuação dos professores em relação às brincadeiras. Assim, propõe um encontro colaborativo, sessões reflexivas e observações colaborativas como procedimentos de produção de dados, na busca por traçar um perfil dos participantes da pesquisa, proporcionar uma formação a partir dos temas associados ao brincar na El (abordando os conceitos de colaboração, sentido/significado, atividade e brincar por meio das sessões reflexivas) e propiciar uma reflexão com as professoras acerca das práticas pedagógicas em sala de aula, vinculadas à brincadeira. Nesse contexto, a autora critica a utilização da brincadeira para finalidades conteudistas, pautadas numa abordagem didática associada a uma expectativa de aprendizagem que utiliza a brincadeira como ferramenta de ensino. Assim, advoga por um espaço destinado ao brincar que abarque outras dimensões, que por vezes não estão vinculadas a uma finalidade específica, defendendo a brincadeira e sua finalidade em si mesma.

Em consonância com esses pressupostos, o trabalho de Neitzel (2012) também problematiza a brincadeira como recurso para o ensino de conteúdos, bem como uma lógica do brincar como entretenimento, de modo a ocupar um lugar secundário no cotidiano da El (somente no recreio e final da aula, como atividade menos importante). Tais resultados foram produzidos com a realização de uma pesquisa orientada pelo método clínico piagetiano, a partir de entrevistas com os professores e observações da rotina em sala de aula, focalizando as concepções docentes sobre a brincadeira na correlação com a aprendizagem.

No que concerne ao papel do professor nas situações de brincadeira, a pesquisa aponta para a função de solucionar problemas - como no caso da disputa por brinquedos - ou associada à ideia de cuidado, em que o docente intervém em alguma situação de perigo (quando o balanço está muito alto, por exemplo). Prioriza-se, de acordo com os dados, a interação entre as próprias crianças, de maneira que o professor não ocupe o posicionamento de um adulto brincante, parceiro de brincadeiras. Com as observações, os dados indicaram uma preocupação com o ensino de conteúdos escolares - como a aprendizagem de letras do alfabeto e numerais -, bem como o destaque nas interações entre as crianças, com ênfase na brincadeira simbólica, de modo a vincular o brincar à aprendizagem de convivência com o outro e à socialização, sem a intervenção docente. Presenciadas com menos frequência, a pesquisa captou também proposições de brincadeiras pelos professores, também associadas à ideia de ensinar conteúdos por meio do brincar. Diante do 
pouco envolvimento dos adultos nas brincadeiras, a autora ressalta que a intervenção é necessária nas situações brincantes, de modo que não "sufoque" as crianças e, obviamente, não prejudique a ludicidade presente no brincar.

Tendo em vista tais resultados, Neitzel (2012) assinala que as práticas que abordam o brincar como atividade secundária ou como recurso didático resultam da insuficiência de ações de formação que vinculem o brincar ao desenvolvimento e à aprendizagem das crianças. Desse modo, propõe que a formação de professores na El seja contínua e fundamentada nos princípios interacionistas, baseada em estudos que compreendam o brincar como atividade séria e primordial no trabalho com as crianças.

Ainda que a formação associada ao brincar não seja a questão central da pesquisa de Farias (2012), o trabalho traz importantes contribuições no que concerne à atuação do professor na brincadeira. Abordando as concepções das crianças sobre as características de uma boa professora de El destacamos, dentre as potencialidades do trabalho, a prioridade atribuída às vozes infantis na formação docente como meio de construir um perfil profissional que dialogue com as concepções das crianças sobre uma boa professora. Essas vozes foram captadas por meio de entrevistas coletivas com crianças de duas turmas de El (compostas por crianças de 5 e 6 anos) de instituições diferentes. Além dos procedimentos com as crianças, foram realizadas entrevistas com coordenadoras (para informações sobre a instituição), aplicação de questionário para as professoras (para conhecer as experiências de formação docente) e as famílias (para compreender o contexto social das crianças), bem como a análise das propostas pedagógicas dos centros de $\mathrm{EI}$ (para obter dados que contribuíssem com a pesquisa, especialmente no que se refere à brincadeira). Em síntese, os resultados indicaram que as crianças definem uma boa professora tendo em vista suas características estéticas e modos de ser, articulados às ações de brincar, "pôr de castigo", dar tarefas, entre outras atividades. Destaca-se, nesse propósito de escutar as crianças, a importância de considerar suas vozes nas propostas de formação, principalmente no que diz respeito às atribuições necessárias para o trabalho docente com os pequenos.

Analisando as pesquisas selecionadas, assinalamos que, na observação dos percursos metodológicos, evidenciamos diferentes caminhos pelos quais as pesquisadoras trilharam para a produção dos dados. Os enunciados dos professores, por exemplo, foram evocados por meio de entrevistas individuais (NEITZEL, 2012), questionários (FARIAS, 2012) e encontros colaborativos (COELHO, 2012), de modo a apresentar o que os docentes apontavam quanto ao brincar na El. Destacamos, numa perspectiva bakhtiniana, que, para compreender as enunciações do outro, é preciso considerar "[...] as suas concepções e convicções, os seus preconceitos (do meu ponto de vista), as suas simpatias e antipatias - tudo isso irá determinar a compreensão responsiva do meu enunciado por ele" (BAKHTIN, 2011, p. 302).

Assim como os caminhos metodológicos, os referenciais teóricos também são distintos, destacando sustentação em autores tais como Karl Marx e Lev Vigotsky, apoiados no Materialismo histórico-dialético e na abordagem sócio-histórico-cultural (COELHO, 2012); Jean Piaget, com o método clínico piagetiano (NEITZEL, 2012); bem como Henri Wallon e Lev Vigotsky, na associação de perspectivas sociointeracionistas acerca do desenvolvimento (FARIAS, 2012). 
No que se refere à formação continuada, o conjunto das pesquisas aponta para a indicação desta como recurso privilegiado para enriquecimento das práticas pedagógicas, principalmente com ações formativas pautadas no brincar. Seja como proposta de formação com intervenção (COELHO, 2012), como compreensão das concepções docentes sobre a brincadeira (NEITZEL, 2012) ou como valorização das opiniões das crianças nas ações de formação (FARIAS, 2012), notamos que os trabalhos selecionados trazem contribuições para o campo da El no que concerne à articulação da formação com a brincadeira, especialmente por sinalizarem - dentro de seus contextos de produção - reflexões acerca da atuação docente articulada ao brincar na El. Nesse coletivo polifônico, realçamos como confluências entre os textos a abordagem do papel dos professores em situações de brincadeira (interação, mediação, participação), a importância da presença das práticas brincantes nos espaços e tempos no cotidiano da El, assim como a importância da reflexão sobre o brincar nos momentos de formação continuada.

Os resultados das pesquisas permitem inferir que há uma exigência de que professor valorize as situações de brincadeira, sem perder seu caráter lúdico. Assim, ao mesmo tempo em que é necessário romper com uma lógica escolarizante baseada no ensino de conteúdos específicos, também é preciso que o espaço destinado ao brincar seja primordial, considerando sua importância para o desenvolvimento das crianças. Nesse sentido, verifica-se uma preocupação com a formação continuada como possibilidade de estimular práticas brincantes com as crianças na El, numa perspectiva de formação que fomenta a atuação docente. As pesquisas sinalizam a importância de proporcionar aos profissionais da El uma formação que abarque a brincadeira, propiciando especialmente uma formação teórica fundamentada nas contribuições do brincar para as crianças.

Todavia, como as pesquisas não indicam formas de encaminhamento desses processos formativos, emerge uma noção de formação que parece estarapoiada numa lógica de capacitação, de modo que o estudo sobre a temática do brincar culmine necessariamente em práticas pedagógicas brincantes. Nesse sentido, demarcamos a necessidade de pensarmos a formação para além da acumulação de saberes teóricos, haja vista a reflexão acerca da prática docente como ação primordial nos processos formativos (NÓVOA, 2009).

Essa lógica de formação articulada à atuação também foi indicada nos trabalhos elencados nas reuniões da ANPEd, apresentados a seguir, indicando que tais contextos de divulgação de pesquisas convergem no que se refere aos estudos acerca da formação e do brincar na El.

\section{A FORMAÇÃOEO BRINCAR NA EDUCAÇÃO INFANTIL NAS PESQUISAS DA ANPED}

Em virtude do compromisso e da atuação que visam potencializar o desenvolvimento da qualidade da educação brasileira por meio de pesquisas, elencamos os trabalhos apresentados nas reuniões da $\mathrm{ANPEd}^{3}$, considerando a relevância dessa associação no cenário educacional.

\footnotetext{
3 A Associação Nacional de Pós-Graduação e Pesquisa em Educação (ANPEd) é constituída por professores e estudantes que integram os programas de pós-graduação stricto sensu em educação e pesquisadores associados. Entre seus principais objetivos, destacam-se o incentivo ao desenvolvimento de pesquisas no âmbito da educação, 0 aprimoramento e a consolidação do ensino na pós-graduação, a valorização das novas experiências que emergem no campo da educação, bem como o fortalecimento da pós-graduação no âmbito político. Assim, prioriza-seo incentivo
} 
Reunimos as pesquisas disponíveis no banco de dados dos GT07 - Educação de crianças de 0 a 06 anos - e GT08 - Formação de professores -, mantendo o propósito de busca por trabalhos que articulassem a temática do brincar à formação continuada de professores, no período de 2009 a 2015 (32a à 37ạ reuniões, considerando que os encontros são bienais). Optamos por esse recorte temporal em função do estabelecimento da Resolução no 5, de 17 de dezembro de 2009, que definiu as Diretrizes Curriculares Nacionais para a Educação Infantil (BRASIL, 2009), marco legal que legitima a brincadeira como eixo orientador das práticas pedagógicas na El.

Num primeiro levantamento geral, apuramos um total de 309 trabalhos (124 no GT07 e 185 no GT08). Encaminhamos uma filtragem, considerando os títulos com os descritores Formação continuada e seus derivados (formação contínua, formação permanente, entre outros) e Brincar ou seus termos afins (brincadeiras, atividades lúdicas), elencando inicialmente $29 \operatorname{textos}^{4}$ (sendo 09 decorrentes da busca no GT07 e 20 do GT08). Nas leituras exploratórias dessas pesquisas, constatamos que não houve trabalhos que vinculassem a formação à brincadeira ou a brincadeira à formação como temáticas centrais no campo da El. Com isso, tomamos as temáticas nas suas especificidades, no movimento de buscar, nos estudos relacionados ao brincar (MAYNART, HADDAD, 2012; TEIXEIRA, 2012; BRAGAGNOLO, RIVER, WAGNER, 2013; TEIXEIRA, 2013; CASTRO, 2015; MULLER, 2015), o que há de formação e, nos estudos associados à formação (CÔCO, 2010; LEITE et al, 2010; RIBEIRO, 2012), o que emerge sobre o brincar. Assim, foi possível selecionar 09 trabalhos (07 do GT07 e 02 do GT08), com vistas a estabelecer, por meio da análise documental nas categorias indicadas, pontes de contato entre as pesquisas elencadas.

Tomando o conjunto dos nove trabalhos selecionados (CÔCO, 2010; LEITE et al, 2010; MAYNART, HADDAD, 2012; RIBEIRO, 2012; TEIXEIRA, 2012; BRAGAGNOLO, RIVER, WAGNER, 2013; TEIXEIRA, 2013; CASTRO, 2015; MULLER, 2015), diferentemente dos resultados no levantamento empreendido no banco de dados da CAPES, as regiões que predominaram no que se refere ao quantitativo de trabalhos foram as regiões Sudeste e Sul (33\% cada uma). Posteriormente, temos a região Norte, com $23 \%$ dos trabalhos (que ainda não havia sido mapeada na pesquisa na CAPES) e, por fim, a região Nordeste, com $11 \%$ dos trabalhos.

Assim, no movimento de encontrar aspectos relacionados à formação nos trabalhos que abordam o brincar, vale observar características comuns dessas produções na interface com suas especificidades, com o propósito de compreender como se configuram os trabalhos apresentados na ANPEd quanto à brincadeira. Cabe considerar, como já mencionamos, que esse é um exercício de aproximação das temáticas, objetivando trazer as concepções sobre a brincadeira e a formação nos trabalhos abordados, correlacionando essas temáticas nas análises dos estudos.

No entrecruzamento dos seis trabalhos selecionados que abordam o brincar, destacamos a similaridade em relação à metodologia, que, na totalidade das pesquisas, consiste numa abordagem qualitativa, utilizando instrumentos como filmagem, fotografia e diário de campo como forma de registro dos dados. Tais recursos se configuraram como instrumentos para registrar as situações de brincadeira no decorrer das pesquisas, especialmente na observação das práticas

\footnotetext{
à participação das comunidades acadêmicas e científicas com a finalidade de fomentar as políticas educacionais do país, focalizando as questões relacionadas à pós-graduação.

${ }^{4}$ Os trabalhos selecionados foram apresentados nas modalidades comunicação e pôster.
} 
docentes nos momentos específicos de brincadeira. Em alguns, a realização de entrevistas com os profissionais, com as crianças e com as famílias nas instituições pesquisadas também se constituiu como procedimentos de produção de dados (TEIXEIRA, 2013; MULLER, 2015; CASTRO, 2015).

Com isso, notamos que as pesquisas focalizam as interações entre as crianças ou entre crianças e adultos, focalizando as ações dos sujeitos para produção dos dados. Tal perspectiva apoia-se numa concepção que privilegia os sujeitos, especialmente compreendendo sua singularidade ao ocupar um lugar no mundo (BAKHTIN, 2011). Singularidade que se constitui na interação com o outro, considerando seu caráter social e histórico (BAKHTIN, 2011; VYGOTSKY, 1994).

Nesse sentido, evidenciamos também que um conjunto significativo de trabalhos apresentou uma abordagem histórico-cultural na conceituação do brincar, trazendo como aporte teórico os estudos de Lev Vigotsky em relação à teorização da brincadeira na infância. Essa interlocução com o autor se faz presente especialmente nas duas produções de Teixeira (2012; 2013), nos trabalhos de Bragagnolo, River, Wagner (2013) e Muller (2015), indicando a ancoragem vigotskyana em que tais pesquisas se sustentam.

Empreendendo um diálogo com a formação, vale notar que, embora focalizem as crianças como sujeitos centrais das pesquisas, os trabalhos apontam a formação dos professores como elemento relevante no que concerne ao brincar, principalmente no movimento de atuação com os pequenos. Nesse sentido, prioriza-se uma formação que possibilite ao professor criar condições para as situações de brincadeira, organizando espaços e tempos para brincar, utilizando a brincadeira como recurso para ensino de conteúdos e intervindo nas ações brincantes. Há predominância de uma lógica de mediação e colaboração dos docentes para a ampliação do repertório cultural infantil e para a construção de significados nos momentos de brincadeiras, atribuindo ao adulto um papel relevante no brincar.

Assim, seja explorando as relações de parentesco nas brincadeiras de faz de conta (MAYNART, HADDAD, 2012), a mediação com crianças de uma comunidade ribeirinha (TEIXEIRA, 2012), o planejamento de espaços, tempos e recursos na relação com as brincadeiras das crianças (BRAGAGNOLO, RIVER, WAGNER, 2013), a presença da cultura e da subjetividade nas brincadeiras de faz-de-conta de crianças ribeirinhas (TEIXEIRA, 2013), o uso de tecnologias móveis na El na perspectiva das crianças (MULLER, 2015) ou o papel do docente na constituição da linguagem e nas brincadeiras das crianças (CASTRO, 2015), os trabalhos que tematizam o brincar comunicam também acerca da formação.

Cabe considerar, no conjunto das seis produções em análise, que, mesmo circunscrevendo aspectos distintos dentro da temática da brincadeira, as pesquisas apontam a formação como meio de aprimorar a prática docente, indicando a necessidade de inves timento nos es paços de formação que tematizem a brincadeira e seus desdobramentos nas atividades com as crianças. Em síntese, as concepções sobre a formação e o brincar se articulam, na medida em que prevalece uma lógica de formação que incentive o professor a brincar e a promover situações de brincadeira. O brincar, nesse sentido, ganha centralidade nas práticas pedagógicas, que devem ser estimuladas em contextos de formação. 
Destacamos também a diversidade de movimentos formativos que sustentam as pesquisas, traduzidos especialmente em experiências e propostas de formação na interlocução com o desenvolvimento profissional docente. Assim, as pesquisas confluem para uma formação de caráter contínuo, de modo a perpassar toda a trajetória do professor num movimento permanente que, por sua vez, acena para mudanças, inovações e transformações nas práticas pedagógicas.

Com relaçãoàs pesquisas que mencionam a brincadeira no escopo da formação, elencamos os trabalhos de Côco (2010), Leite et al (2010) e Ribeiro (2012). A pesquisa de Côco (2010) delineia as ações de formação continuada na articulação com o investimento das políticas públicas na El. Assim, tendo em vista o fomento à formação proporcionada à El com sua inserção nos sistemas de ensino, os projetos de formação mobilizados pelas secretarias dialogam com as premissas da formação continuada como um direito dos professores, criando iniciativas que visam responder a garantia de espaços de formação aos profissionais da El.

Essas ações de formação se constituem de diferentes formas (grupos de estudos, participação em eventos, realização de mostras culturais, entre outras) e com diferentes parceiros institucionais (coordenação de profissionais das próprias secretarias, convidados, contratados e/ou em parceria com outras instituições, como faculdades e empresas). Os dados da pesquisa indicam também que a formação se destina com mais ênfase aos professores, principalmente por se constituírem em maior número no cenário educativo, desconsiderando que o contexto da $\mathrm{EI}$ reúne um conjunto mais ampliado de profissionais. O brincar, nesse trabalho, se situa como temática no campo de estudo dos projetos de formação proporcionado pelas secretarias de educação, indicado juntamente com as temáticas lúdicas "jogos", "música" e "teatro", no conjunto das abordagens nas ações de formação. Nesse sentido, ainda que o estudo de Côco (2010) revele que a brincadeira não seja o tema de maior destaque, uma vez que aparece com menor frequência se comparada aos temas relacionados Alfabetização, leitura e escrita, Diversidade, inclusão, educação no campo e cultura afro-brasileira, bem como a Gestão, projeto-político-pedagógico, proposta pedagógica e planejamento, pode ser considerada um campo de estudos relevante na El. Assim, se torna válido valorizar sua inserção nesse coletivo de temas e, concomitantemente, indicar a necessidade de dedicar mais atenção a essa temática, considerando sua centralidade no trabalho educativo com as crianças.

Também mencionando o brincar em sua pesquisa, Leite et al (2010) buscaram identificar as principais necessidades formativas de professores de Educação Infantil e Ensino Fundamental (EF). Juntamente com o escopo Metodologia/ música/ilustração de histórias, os jogos e brincadeiras foram citados pelos professores de EF como aspectos "fáceis" de ser trabalhados na disciplina de língua portuguesa. Mesmo que o questionário tenha focalizado os conteúdos referentes a essa disciplina, as autoras salientaram a importância da abordagem do brincar nos contextos de formação contínua, pois, mesmo que não se cons titua como um conteúdo, a presença da brincadeira nas ações de formação se torna fundamental.

Tal pesquisa também envolveu professores de El, haja vista sua realização com 533 professores de escolas públicas de dez municípios do interior de São Paulo. Todavia, especialmente nesse trabalho, as autoras optaram por trazer com mais ênfase os dados relativos às necessidades formativas dos professores de EF, principalmente com relação aos conteúdos de Língua portuguesa e Matemática. Salientamos que seria interessante conhecer as necessidades formativas dos 
professores de El desse contexto, compreendendo também qual seria o espaço da brincadeira enquanto temática a ser abordada nessas ações de formação.

O trabalho de Ribeiro (2012) prioriza a escrita de professores das séries iniciais do EF do Rio de Janeiro em registros de classe, entendendo esse movimento como política de formação continuada. Com esse propósito, analisa tais registros, bem como questionários sobre a escrita nos registros, respondidos pelos professores. Como proposta de trabalho, relatada nos registros de classe de uma das professoras, o brincar foi compreendido como recurso para o ensino de práticas de leitura e escrita, de modo a permitir, segundo a docente que efetuou o registro, uma alfabetização "mais agradável e gratificante para o grupo" (RIBEIRO, 2012, p.11). Nota-se, assim, que o papel da brincadeira nessa proposta foi proporcionar um ensino mais lúdico e prazeroso, de forma que o brincar não se constituiu como uma atividade em si mesma, mas como um instrumento utilizado para alfabetizar.

Indicando a pertinência de visibilizar ações de formação coletiva e entre pares, o conjunto dos trabalhos indica que o brincar constitui-se como temática abordada nos encontros de formação e/ou é assinalado como um tema necessário à formação, visto que os professores indicam sua presença nos contextos formativos. Sinalizamos, nesse escopo, que emerge um es paço potente para novos estudos, que podem compreender como o brincar enquanto temática é abordado nas ações de formação, uma vez que os estudos apresentados não focalizaram tal objetivo.

Diante do exposto, nesse exercício de compreender o que dizem os trabalhos sobre o brincar quanto à formação e como os trabalhos que dizem sobre a formação abordam a brincadeira, exploramos a vinculação dessas temáticas no contexto da El. Em síntese, podemos inferir que as pesquisas sobre o brincar indicam a necessidade de investimento em encontros formativos que tematizem a brincadeira. Quanto às pesquisas que abordam a formação, o brincar é apontado como temática explorada nos processos formativos e, ainda, como recurso didático nos registros do trabalho docente.

Nesse movimento de interlocução com as produções acadêmicas, passamos à abordagem do levantamento das pesquisas na SCIELO buscando compreender quais periódicos abordam a brincadeira, a formação e a El, perquirindo a compreensão de como os trabalhos articulam tais temáticas.

\section{A FORMAÇÃO E O BRINCAR NA EDUCAÇÃO INFANTIL NOS PERIÓDICOS DA SCIELO}

Mantendo a associação dos descritores Formação e Brincar, com a busca no banco de dados da SCIELO ${ }^{5}$ apuramos sete trabalhos numa primeira incursão. A análise desse primeiro conjunto

\footnotetext{
5 Proporcionando acesso a artigos publicados em periódicos el etrônicos, a Scientific Electronic Library Online (SciELO) objetiva preparar, armazenar, disseminar e avaliar as pesquisas disponíveis em periódicos. Reunindo uma coleção de textos, a SciELO fornece uma biblioteca eletrônica de pesquisas relevantes no bojo das produções científicas, constituindo-se como um banco de dados que se originou da articulação entre a Fundação de Amparo à Pesquisa do Estado de São Paulo (FAPESP) em parceria como Centro Latino-Americano e do Caribe de Informação em Ciências da Saúde a (BIREME) e apoiados pelo Conselho Nacional de Desenvolvimento Científico e Tecnológico (CNPq).
} 
de produções revelou que somente um apresentava uma relação de proximidade com nosso estudo. Continuando a busca, numa segunda incursão buscamos trabalhos que vinculassem o Brincar à Educação Infantil, sem atrelar a abordagem à formação, tendo sido possível levantar 21 trabalhos (dentre eles, aquele mencionado no primeiro levantamento como único trabalho com proximidade da temática).

Numa análise das áreas de vinculação, observamos que 09 se situam em periódicos na área da Psicologia (42,8\%), 07 no campo da Educação (33,3\%), 03 na Educação Física (14,2\%) e 02 na área da Enfermagem (9,5\%), acenando para os diferentes campos de conhecimento que investem nas produções associadas ao brincar e à El. Embora haja articulação entre as áreas, verifica-se uma presença significativa de pesquisas que focalizam a brincadeira publicadas nas revistas do campo da Psicologia. Diante desse levantamento, assinalamos a diversidade de áreas que vêm pesquisando o brincar, indicando que a temática perpassa distintas pesquisas, que envolvem, como escopo comum, a abordagem das crianças na interface com o brincar. No reconhecimento dos distintos enunciados que dizem sobre o brincar e a El, oriundos das diferentes áreas, assinalamos as várias perspectivas que emergem, tocando "milhares de fios ideológicos" (BAKHTIN, 1993, p. 86) que dialogam com essas temáticas.

Quanto à regionalidade identificada na totalidade das pesquisas, verifica-se a predominância dos periódicos da região Sudeste (57\%), seguidos da região Sul (33\%) e CentroOeste (10\%) - sendo que os trabalhos oriundos desta última ainda não haviam se manifestado nos bancos anteriores. Evidenciamos que, apesar de estudos vinculados à região Norte e Nordeste não terem sido identificados nessa busca, tais regiões foram mencionadas no levantamento empreendido nos outros bancos, acenando a presença de trabalhos oriundos de todas as regiões do país, haja vista o conjunto de textos contemplados neste estudo.

Retomando o grupo de 21 estudos, ainda que apurados com os descritores referentes ao Brincar e à Educação Infantil, numa exploração mais minuciosa, foi possível identificar 03 pesquisas que abordam a formação associada à brincadeira na EI (LORDELO, CARVALHO, 2003; VECTORE, 2003; NAVARRO, PRODÓCIMO, 2012).

$\mathrm{Na}$ abordagem dessas três pesquisas selecionadas, destacamos que o trabalho de Lordelo e Carvalho (2003) discute o lugar do brincar no currículo da El, pontuando questões referentes aos espaços e tempos destinados à brincadeira nas instituições de atendimento à pequena infância. Desse modo, as autoras apontam as atividades escolares como ações privilegiadas no trabalho com as crianças, em detrimento dos momentos de brincadeira. O lugar do brincar, nessa perspectiva, se situa anteriormente ou posteriormente ao desenvolvimento das atividades, comumente no início ou no fim da jornada diária, ocupando um espaço secundário nas práticas pedagógicas. Abordando o conceito de motivação nos estudos da psicologia do desenvolvimento, o estudo preconiza a organização dos espaços como movimento propiciador do brincar, de modo a estimular a brincadeira criando condições para tal. Nesse sentido, a pesquisa também aponta para uma proposta de formação de professores que priorize o incentivo de experiências de aprendizagem, distanciando o trabalho educativo com as crianças do modelo escolar que ainda se constitui como predominante em algumas instituições de El. 
O estudo de Vectore (2003) se baseia no programa de desenvolvimento profissional MISC (Mediational Intervention for Sensitizing Caregivers), cuja lógica se fundamenta na intervenção mediacional como recurso para modificar as variáveis de comportamento nas interações sociais e, especialmente na referida pesquisa, no trabalho com as crianças. Assim, define a focalização, a expansão, a afetividade/mediação do significado, a recompensa e a regulação como comportamentos resultantes de uma mediação de qualidade, apostando nesses movimentos de intervenção como formas de atuação no processo educativo. Tais comportamentos são abordados como critérios de análise, nos quais a autora se sustenta para analisar a atuação de educadores infantis em situações de brincadeira. Nesse sentido, a pesquisa busca encontrar, nas ações dos professores, características presentes no programa de formação MISC, compreendendo suas definições como um parâmetro relevante no que diz respeito a uma mediação de qualidade. Considerando os resultados obtidos por meio de observações, a autora acena para a pertinência da capacitação dos profissionais de El, considerando a eficiência do programa abordado na interface com a intervenção mediacional. A pesquisa sugere uma proposta de formação continuada que contemple a mediação como elemento central nas práticas pedagógicas, assinalando para a reflexão sobre a ludicidade no trabalho educativo com as crianças. As situações de brincadeira, nesse sentido, se constituem como relevantes possibilidades de mediação, principalmente na medida em que o educador adquire uma formação para atuar intencionalmente na interação com as crianças.

Esse caráter intencional relacionado à mediação também é privilegiado na pesquisa de Navarro e Prodócimo (2012), cujo objetivo consiste em identificar as influências das diversas maneiras de mediação do professor nas brincadeiras das crianças. Para isso, empreendem uma pesquisa descritiva, em que são analisadas diferentes formas de mediação no brincar, como a observação em situações de brincadeira livre, a participação do professor em momentos de brincar e a intervenção com realização de uma proposta de brincadeira conduzida pelo professor.

Assim, a partir da identificação desses modos de mediação, as autoras assinalam para os distintos desdobramentos que a ação docente possibilita nos momentos de brincadeira, tendo em vista a atuação do professor como mediador na interação com as crianças. A necessidade da mediação está baseada em referenciais como Gilles Brougère e Lev Vigotsky, numa perspectiva que considera o papel fundamental da brincadeira no desenvolvimento infantil e, nesse sentido, a atuação do professor como estimulador desse processo. Orientadas por esses conceitos, as autoras questionam a formação dos professores que atuam na El, focalizando a relevância da abordagem da função docente nas situações de brincadeira nos cursos que visam formar esses profissionais.

Tendo em vista a totalidade dos trabalhos abordados, os procedimentos metodológicos indicam, assim como nos trabalhos abordados na ANPEd, a valorização das situações de brincadeiras nos espaços e tempos na El, focalizando as observações das interações entre os sujeitos. Assim, as pesquisas priorizam as relações que ocorrem no cotidiano das instituições, destacando as situações de brincadeira e as aprendizagens decorrentes desse processo, entendendo, por se ancorarem numa perspectiva histórico-cultural, que o brincar conduz e determina o desenvolvimento da criança (VYGOTSKY, 1994).

No conjunto dos textos, ganha destaque um conceito bastante abordado nos estudos da psicologia do desenvolvimento: a mediação. Essa incidência ocorre provavelmente devido à 
inserção das pesquisas num contexto de produção da área da Psicologia, em que a referência à brincadeira na interface com a mediação circunscreve uma perspectiva de desenvolvimento das crianças por meio do brincar. Nesse sentido, a preocupação com espaços para brincar, o incentivo à brincadeira e, mais ainda, a indicação de investimentos em propostas de formação de professores que propiciem estudos relacionados ao brincar demarcam as principais contribuições das pesquisas. Com isso, reiteramos um espaço para a produção de novos estudos que, além de propor um investimento na formação, situem a brincadeira na formação, buscando compreender como o brincar é abordado nos espaços formativos.

De modo geral, considerando as diferentes abordagens das pesquisas, nota-se uma expectativa de que a formação estimule os professores a privilegiar a brincadeira nas práticas pedagógicas, numa ideia de atuação que ocorre mediante um contexto formativo. Assim, este estudo assinala que, nos acúmulos da produção acadêmica que tematiza a formação e o brincar tendo como referência o contexto da El, predomina uma lógica baseada na necessidade de que o professor esteja num contínuo processo de formação, especialmente com a participação em encontros de formação continuada, com a finalidade de des envolver um trabalho educativo com as crianças pautado no brincar. Nessa perspectiva, cabe ainda observar os investimentos em orientações ao trabalho docente na El, visando fomentar práticas brincantes nesse contexto (BRASIL, 2012). Em suma, com este estudo assinalamos a emergência de um contexto que vem marcando a articulação entre as temáticas da formação e do brincar, no bojo do desenvolvimento do trabalho educativo na El.

\section{CONSIDERAÇÕES FINAIS}

Diante do estudo empreendido neste texto, tecemos algumas considerações acerca dos trabalhos elencados, com o intuito de sintetizar a articulação entre a formação, a brincadeira e a EI nas discussões apresentadas nas produções acadêmicas. Nesse movimento, exploramos tais temáticas na configuração dos trabalhos, compreendendo como a formação e o brincar estão sendo abordados no contexto da El.

Partindo da premissa de que esses trabalhos integram a teia dialógica da comunicação discursiva, se constituindo como elos em meio aos enunciados outros, que antecedem e sucedem a diversidade de enunciações que comunicam acerca das temáticas em curso (BAKHTIN, 2011), destacamos a importância de mobilizar a interlocução entre os trabalhos produzidos, compreendendo as principais discussões no campo da El, especialmente no que concerne à formação continuada e à brincadeira.

A formação, nos trabalhos apresentados, centraliza-se no bojo da reflexão sobre a atuação docente, sustentada numa concepção de formação que ocorre em consonância com a prática pedagógica. Na vinculação com o brincar, predomina a constatação de que os processos formativos evocam uma atuação docente pautada na promoção de situações de brincadeiras, defendendo uma formação que fomente os estudos relacionados ao brincar, culminado num trabalho educativo em que a brincadeira se constitua como eixo. Nessa perspectiva, os estudos indicam a necessidade de formar um professor que seja mediador, apostando na mediação como movimento de desenvolvimento e aprendizagem das crianças a partir do brincar. 
Notamos que um conjunto significativo de pesquisas aponta para a secundarização dos momentos de brincadeira nos espaços e tempos da $\mathrm{El}$, sendo priorizadas as atividades associadas à escolarização nas instituições de atendimento à pequena infância. As pesquisas problematizam a utilização da brincadeira apenas como recurso didático, bem como a ocorrência de situações de brincadeira na ocupação de espaços vagos no planejamento das atividades. Assim, acenamos para a importância de refletir sobre o trabalho educativo com as crianças, compreendendo a brincadeira como atividade privilegiada de aprendizagem, de desenvolvimento e, sobretudo, de interação com o outro.

Em suma, as análises acenam para a necessidade de investimentos em ações de formação continuada que tematizem o brincar, com a finalidade de culminar em práticas pedagógicas apoiadas na brincadeira. Nesse sentido, ressaltamos que o interesse em analisar a produção acadêmica, considerando as diferenças de enfoques entre as abordagens teórico-metodológicas, expressou o debate sobre a formação continuada na El na interface com o brincar como campo de estudo em construção, configurando-se na expressão do reconhecimento da importância da pesquisa. A capacidade de revelar e validar o conhecimento dos bancos de estudos sobre o tema em questão apontou diferentes implicações e desafios para o campo da pesquisa sobre a formação de professores, ressaltando, assim, a importância de articular a formação continuada à brincadeira, de modo a compreender as possibilidades formativas que englobem o brincar, bem como a diversidade de situações brincantes, tendo em vista as múltiplas formas de brincar e as interações entre os sujeitos nesse processo.

\section{REFERÊNCIAS}

1. ANDRÉ, M. (Org.). Formação de professores no Brasil (1990-1998). Brasília: Inep/Anped/Comped, 2002. Disponível em: <file:///C:/Users/user/Downloads/formaca o _de_professores_148.pdf>. Acesso em: 8 set. 2015

2. BAKHTIN, M. M. Estética da criação verbal. 6. ed. São Paulo: WMF Martins Fontes, 2011

3. BAKHTIN, M. M. Questões de literatura e de estetica: (a teoria do romance). 3. ed. - São Paulo: UNESP: Hucitec, 1993.

4. BRAGAGNOLO, R. I.; RIVERO, A. S.; WAGNER, Z. T. Entre meninos e meninas, lobos, carrinhos e bonecas: a brincadeira em um contexto da educação infantil. In: REUNIÃO ANUAL DA ANPEd, 36., 2013. Anais... Goiânia: ANPEd, 2013. Disponível em: <http://36reuniao.anped. org.br/pdfs_trabalhos_aprovados/gt07_trabalhos_pdfs/gt07_3157_textt.pdf> Acesso em 15 ago. 2015

5. BRASIL. CNE/MEC. Brinquedos e brincadeiras de creches: manual de orientação pedagógica. Brasília: MEC, 2012. Disponível em: <http://portal.mec.gov.br/index.php?option=com_doc man\&view=download\&alias=12451-publicacao-brinquedo-e-brincadeiras-completa-pdf\&ca tegory_slug=janeiro-2013-pdf\&Itemid=30192> Acesso em: 22 nov. 2015

6. BRASIL. CNE/MEC. Resolução no 2, de 10 de julho de 2015. Define as Diretrizes Curriculares Nacionais para a formação inicial em nível superior (cursos de licenciatura, cursos de formação pedagógica para graduados e cursos de segunda licenciatura) e para a formação continuada. Disponível em: <http://ced.ufsc.br/files/2015/07/RES-2-2015-CP-CNE-Diretrizes-Curriculares Nacionais-para-a-forma\%C3\%A7\%C3\%A3o-inicial-em-n\%C3\%ADvel-superior.pdf $>$ Acesso em: 
05 ago. 2015.

7. BRASIL. CNE/MEC. Resolução no 5, de 17 de dezembro de 2009. Estabelece Diretrizes Curriculares para a Educação Infantil. Disponível em: <http://portal.mec.gov.br/index. php? option=com_docman\&task=doc_download\&gid=2298\&ltemid>. Acesso em: 19 mai.2015

8. BRZEZINSKI, I.; Formação de profissionais da educação (2003-2010). Brasília: INEP/ANPEd, 2014. Disponível em: <file:///C:/Users/user/Downloads/1411408507Estadoconhecimento13 \%20(1).pdf> Acesso em: 8 set. 2015

9. BRZEZINSKI, I.; GARRIDO, E. Formação de profissionais da educação (1997-2002). Brasília: INEP/ANPEd, 2006. Disponível em: file://C:/Users/user/Downloads/\%7BE7938201-82644C46993509B88283020F\%7D_MIOLO_ESTADO\%20DO\%20CONHECIMENTO\%20N\%C2\%BA\% 2010\%20(3).pdf. >. Acesso em: 8 set. 2015

10. CASTRO, J. S. "Quando elas não querem mais ficar juntas fazendo, deixo elas pegarem brinquedos e brincarem": os atos docentes como promotores da brincadeira e da linguagem entre as crianças pequeninas. In: REUNIÃO ANUAL DA ANPEd, 37., 2015. Anais... Florianópolis: ANPEd, 2015. Disponível em: <http://37reuniao.anped.org.br/wp-content/uploads/2015/02/ P\%C3\%B4ster-GT07-3978.pdf.> Acesso em: 15 ago. 2015

11. CÔCO, V. Formação continuada na educação infantil. In: REUNIÃO ANUAL DA ANPEd, 33., 2010. Anais... Caxambu: ANPEd, 2010. Disponível em: <http://33reuniao.anped.org.br/33en contro/app/webroot/files/file/Trabalhos\%20em\%20PDF/GT07-6078--Int.docx.pdf> Acesso em: 15 ago. 2015

12. COELHO, G. M. S. Formação contínua e atividade de ensinar: produzindo sentidos sobre o brincar na educação infantil. 2012. 222f. Dissertação (Mestrado em Educação) - Programa de Pós- Graduação em Educação da Universidade Federal do Piauí. Teresina, 2012.

13. FARIAS, K. C. F. As concepções das crianças sobre as características de uma boa professora de educação infantil. 2012. 156 f. Dissertação (Mestrado em Educação) - Programa de PósGraduação em Educação Brasileira da Faculdade de Educação da Universidade Federal do Ceará. Fortaleza, 2012.

14. LEITE, Y. U. F. et al. Necessidades formativas e formação contínua de professores de redes municipais de ensino. In: REUNIÃO ANUAL DA ANPEd, 33., 2010. Anais... Caxambu: ANPEd, 2010. Disponível em: <http://33reuniao.anped.org.br/33encontro/app/webroot/files/file/ Trabalhos\%20em\%20PDF/GT08-6543--Int.pdf >Acesso em: 15 ago. 2015

15. LORDELO, E. da R; CARVALHO, A. M. A. Educação infantil e psicologia: para que brincar?. Psicol. cienc. prof., Brasília , v. 23, n. 2, p. 14-21, June 2003. Disponível em: $<$ http://www.scielo.br/scielo.php?script=sci_arttext\&pid=S1414-98932003000200004\&Ing=e n\&nrm=iso>. Acesso em 12 Set. 2015.

16. MAYNART, R. C; HADDAD, L. A compreensão das relações de parentesco pelas crianças na brincadeira de faz de conta em contexto de educação infantil. In: REUNIÃO ANUAL DA ANPEd, 35., 2012. Anais... Porto de galinhas: ANPEd, 2012. Disponível em: <http://35reuniao.anped.org.br/images/stories/trabalhos/GT07\%20Trabalhos/GT072066_int.pdf. >Acesso em: 15 ago. 2015

17. MULLER, J. C. Jogos e brincadeiras com o uso das tecnologias móveis na educação infantil: o que as crianças têm a nos dizer? In: REUNIÃO ANUAL DA ANPEd, 37., 2015. Anais... Florianópolis: ANPEd, 2015. Disponível em: <http://37reuniao.anped.org.br/wp- 
content/uploads/2015/02/Trabalho-GT07-4367.pdf. >Acesso em: 15 ago. 2015

18. NAVARRO, M. S.; PRODOCIMO, E. Brincar e mediação na escola. Rev. Bras. Ciênc. Esporte, Porto Alegre, v. 34, n. 3, p. 633-648, Set. 2012 . Disponível em: <http://www.scielo.br/ scielo.php?script=sci_arttext\&pid=S0101-32892012000300008\&lng=en\&nrm=isoAcesso em: 12 set. 2015.

19. NEITZEL, S. T. L. Brincadeira e aprendizagem: concepções docentes na Educação Infantil. 2012. 112 f. Dissertação (Mestrado em Educação) - Programa de Pós- Graduação em Educação da Faculdade de Educação da Universidade Federal do Rio Grande do Sul. Porto Alegre, 2012.

20. NÓVOA, A. Formação de professores e trabalho pedagógico. Lisboa: Educa, 2002.

21. NÓVOA, A. Professores: Imagens do futuro presente. Lisboa: Educa, 2009.

22. RIBEIRO, L. A. O registro de classe das escolas públicas municipais do rio de janeiro: formação docente continuada ou tarefa burocrática? . In: REUNIÃO ANUAL DA ANPEd, 35., 2012. Anais... Porto de galinhas: ANPEd, 2012. Disponível em: <http://35reuniao.anped.org.br/ima ges/stories/trabalhos/GT08\%20Trabalhos/GT08-2103_int.pdf> Acesso em: 15 ago. 2015

23. ROCHA, E. A. C. As pesquisas sobre educação infantil no Brasil: a trajetória da Anped (19901996). Pro-posições, Campinas, n. 28, p. 54-74, 1999. Disponível em: < http://www.todos nos.unicamp.br:8080/lab/acervo/artigos-de-periodicos/ROCHA_AsPesqui sasSobreEducacaolnfanti_In_Pro-Posicoes.rtf/view>. Acesso em: 5 set. 2015.

24. TEIXEIRA, S. R. S. A mediação de uma professora de educação infantil nas brincadeiras de fazde-conta de crianças ribeirinhas. In: REUNIÃO ANUAL DA ANPEd, 35., 2012. Anais... Porto de galinhas: ANPEd, 2012. Disponível em: <http://35reuniao.anped.org.br/images/stories/ trabalhos/GT07\%20Trabalhos/GT07-2078_int.pdf. >Acesso em: 15 ago. 2015

25. TEIXEIRA, S. R. S. A relação cultura e subjetividade nas brincadeiras de faz de conta de crianças ribeirinhas da Amazônia. In: REUNIÃO ANUAL DA ANPEd, 36., 2013. Anais... Goiânia: ANPEd, 2013. Disponível em: <http://36reuniao.anped.org.br/pdfs_trabalhos_aprovados /gt07_trabalhos_pdfs/gt07_3369_texto.pdf> Acesso em: 15 ago. 2015

26. VECTORE, C. O Brincar e a Intervenção Mediacional na Formação Continuada de Professores de Educação Infantil. Psicol. USP, São Paulo, v. 14, n. 3, p. 105-131, 2003 . Disponível em: $<$ http://www.scielo.br/scielo.php?script=sci_arttext\&pid=S010365642003000300010\&lng=en\&nrm=iso>. Acesso em: 12 set. 2015.

27. VYGOTSKY, L. S. A formação social da mente: o desenvolvimento dos processos psicológicos superiores. 5. ed. - São Paulo: Martins Fontes, 1994. 